\title{
Extending Isotope in Precipitation Data Beyond Direct Measurements: The Perspective From Glacier Ice-Core Measurements in Switzerland
}

\author{
UlRich SchottereR $^{1}$ aNd Willibald STICHLER ${ }^{2}$ \\ ${ }^{1}$ Climate and Environmental Physics and Department of Chemistry, University Bern, Switzerland; schotterer@climate.unibe.ch \\ ${ }^{2}$ GSF-Institute for Hydrology, Neuherberg, Germany; willibald.stichler@gsf.de
}

For paleoclimatic applications of stable isotope records two premises have to be fulfilled, namely, (1) that the isotope composition of the proxy material can be related to the water cycle of the past, and (2) that the relevant hydroclimatic parameters contributing to the record can be evaluated. Ice cores clearly play a central role within the goal of ISOMAP, because they potentially provide one of the most direct archives of paleoprecipitation, yet basic monitoring and process studies in situ are required to ensure that the transfer functions between the isotopic composition of the precipitation that is preserved and the conditions at the time of its formation are clearly elucidated.

Isotopes have been measured regularly in monthly composites of precipitation in Switzerland since 1970. The official Swiss network for isotopes in the hydrological cycle, operated by the Federal Office for Water and Geology, became operational in 1992. The network data cover the principal hydrometeorological regions of Switzerland at different altitudes, and therefore afford a unique opportunity to extend data records back in time via linking with high-resolution measurements from ice cores (or other archives).

Particularly well-resolved ice-core records have been obtained from the cold Fiescherhorn Plateau, situated in the Berner Oberland at an elevation of $3950 \mathrm{~m}$ (see Frontpage and upper panel, Fig. 1), which was drilled in both 1987 and 2000. The glacier is characterized by a notably high accumulation rate (1-2 $\mathrm{m}$ of water equivalent per year), potentially providing extremely fine temporal resolution. Isotopic determinations $\left(\delta^{18} \mathrm{O}, \delta^{2} \mathrm{H},{ }^{3} \mathrm{H}\right)$ were accompanied by measurement of a suite of relevant environmental tracers at close intervals, constituting up to 35 samples per year. As shown in Figure 1 (middle panel), systematic annual

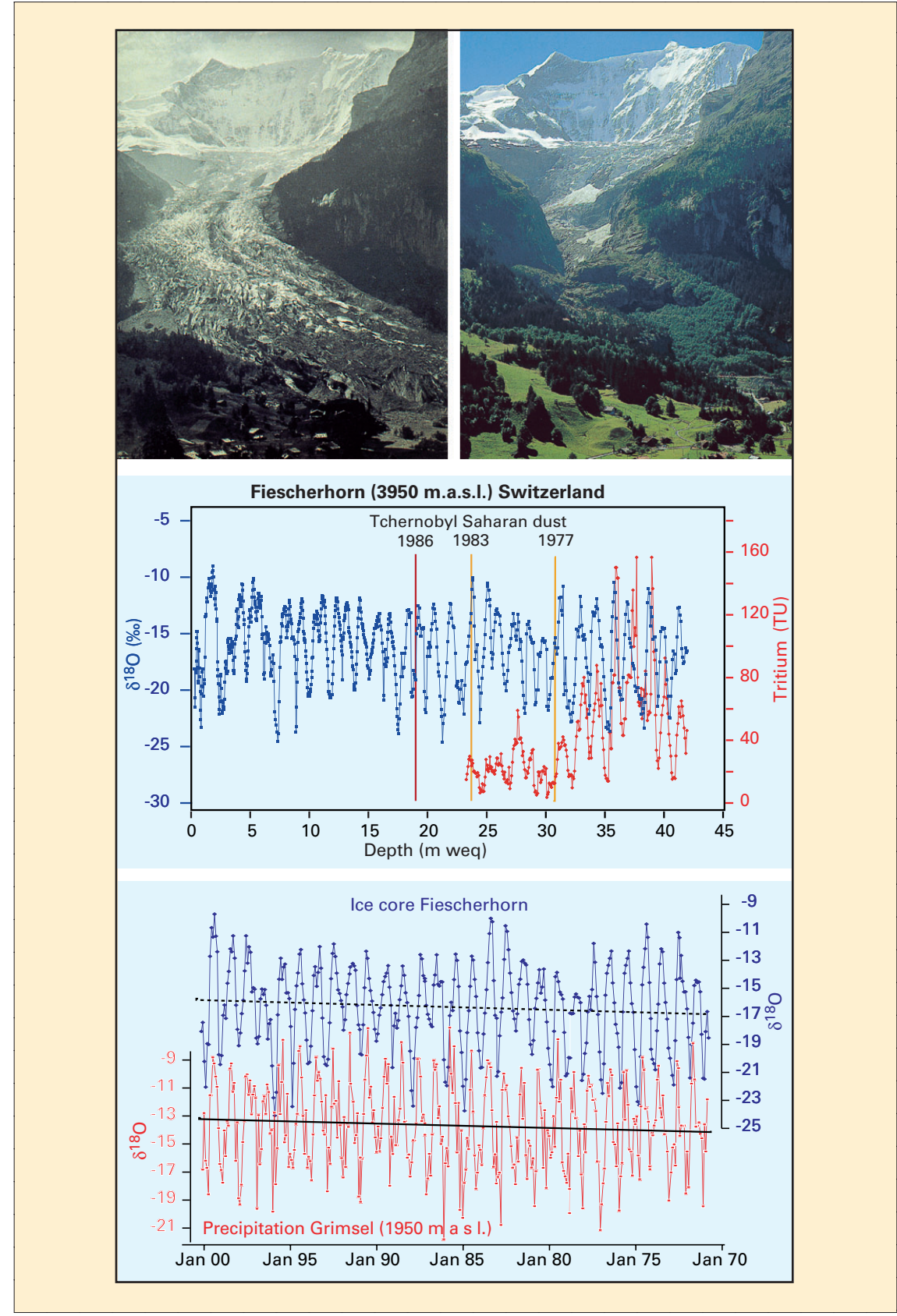

Fig. 1: Two views of the Lower Grindelwald Glacier, Fiescherhorn, from the same vantage point, revealing significant retreat between 1858 (left) and 1974 (right). The middle panel shows the stacked ice core $\delta^{18} \mathrm{O}$ record for 1970-2000 in terms of depth (metres water equivalent), in company with the ${ }^{3} \mathrm{H}$ record and key time markers. The lower panel illustrates the same $\delta^{18} \mathrm{O}$ record in terms of time, calibrated against the $\delta^{18} \mathrm{O}$ record of monthly composite precipitation from Grimsel. Although both records share the same strong annual cycle and longterm trend, remarkably weak correlation exists at finer scale.

cycles of variation in $\delta^{18} \mathrm{O}$ are clearly apparent for the entire Fiescherhorn record, anchored on some discrete time markers, suggesting that the series is continuous and complete. Given this unprecedented degree of resolution and the quality of ac- companying meteorological information, this data set should be ideally suited for rigorous evaluation of the hydrometeorological information archived in this alpine glacier.Yet this task is not straightforward, since the challenge of defin- 


\section{Science Highlights}

ing an absolute "ice-core calendar", to permit direct comparison with contemporaneous isotopic and meteorological data, still persists: Although the data measured in the ice core provide unmistakable evidence for the passage of time, where does a particular month (or season or year) actually begin and end? Thus, in spite of the unusually high resolution, the Fiescherhorn ice-core chronology may not be able to support evaluation of isotope-climate relations with the same level of confidence or at temporal scales equivalent to that possible using data from sampling of monthly composite precipitation.

Indeed, this limitation can be demonstrated by comparing the stacked Fiescherhorn $\delta^{18} \mathrm{O}$ record with the monthly composite precipitation $\delta^{18} \mathrm{O}$ record from Grimsel, a high-elevation station (1950 m) less than $25 \mathrm{~km}$ distant (lower panel, Fig. 1). Even extensive adjustment to achieve a best-fit with this monthly time-series yields only weak correlation, in spite of the visual impression imparted by the strong

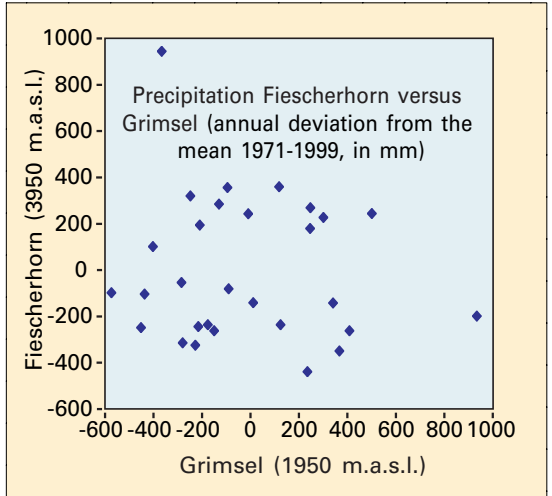

Fig. 2: Comparison of net annual accumulation at Fiescherhorn and precipitation amount at Grimsel. The lack of correspondence, consistent with the weak isotopic correlation evident in Fig. 1, underscores the need for critical evaluation of alpine ice core records.

annual cycling in both records and the similar longterm trends. Subsequent comparison with the North Atlantic Oscillation index (not shown), which generally correlates significantly with composite monthly European isotope records, also reveals weak correspondence. The most likely explanation to account for the apparent deficiency in the ability of this glacier to archive paleoprecipitation is revealed clearly by the plot shown in Figure 2, which shows that no cor- respondence exists between the net annual accumulation at Fiescherhorn and the amount of annual precipitation at Grimsel. This probably reflects at least in part the influence of drifting and other postdepositional processes that remove or redistribute snow, reminding us that alpine glaciers (and certainly to some extent polar ice sheets) are dynamic, open systems for precipitation, and that due caution is required in attempting to decipher their isotopic records.

\section{REFERENCES}

Schotterer, U., Schwarz, P. and Rajner, V., 1998: From pre-bomb levels to industrial times: A complete tritium record from an alpine ice core and its relevance for environmental studies. Proceedings, Isotope Techniques in the Study of Environmental Change, IAEA, Vienna, Vienna, April 1997, IAEASM-349, 581-590.

Schotterer, U., Stichler, W., Graf, W., Bürki, H.U., Gourcy, L., Ginot, P. and Huber, T., 2002: Stable isotopes in alpine ice cores: Do they record climate variability? Proceedings, International Conference on the Study of Environmental Change Using Isotope Techniques, Vienna, April 2001, IAEA-CN-80.

Stichler, W. and Schotterer, U., 2000: From accumulation to discharge: modification of stable isotopes during glacial and postglacial processes. Hydrological Processes 14: 1423-1438.

\section{Holocene Variability in the Indian Ocean Monsoon: A Stalagmite- Based, High-Resolution 0xygen Isotope Record from Southern Oman}

\footnotetext{
Dominik Fleitmann ${ }^{1}$, Stephen J. Burns ${ }^{2}$, Manfred Mudelsee ${ }^{3}$, Ulrich NefF ${ }^{4}$, Jan Kramers ${ }^{1}$, Augusto Mangini ${ }^{4}$ and Albert Matter ${ }^{1}$

1 Institute of Geological Sciences, University of Bern, Switzerland; fleitman@geo.unibe.ch, kramers@geo.unibe.ch, albert.matter@geo.unibe.ch

2 Department of Geosciences, Morrill Science Center, University of Massachusetts, USA; sburns@geo.umass.edu

3 Institute of Meteorology, University of Leipzig, Germany; mudelsee@rz.uni-leipzig.de

4 Environmental Physics, Heidelberger Academy of Sciences, Germany; Augusto.Mangini@iup.uni-heidelberg.de
}

The Indian Ocean monsoon is one of the major weather systems on Earth, affecting the economies, agriculture and fisheries of one of the most densely populated areas of the world. To date, analyses of how and why the monsoon varies through time have mainly been restricted to studies of meteorological records, which extend back perhaps $150 \mathrm{yr}$, or to investigations of lacustrine and marine sediments, which have a low time-resolution (typically greater than 100 years) and large age uncertainties. However, one sensitive monitor of monsoon variation having considerably finer temporal resolution is the oxygen isotope composition of stalagmites, such as those from Qunf Cave (17 ${ }^{\circ} 10^{\prime} N, 54^{\circ} 18^{\prime} \mathrm{E}$; 650 m.a.s.I.) in

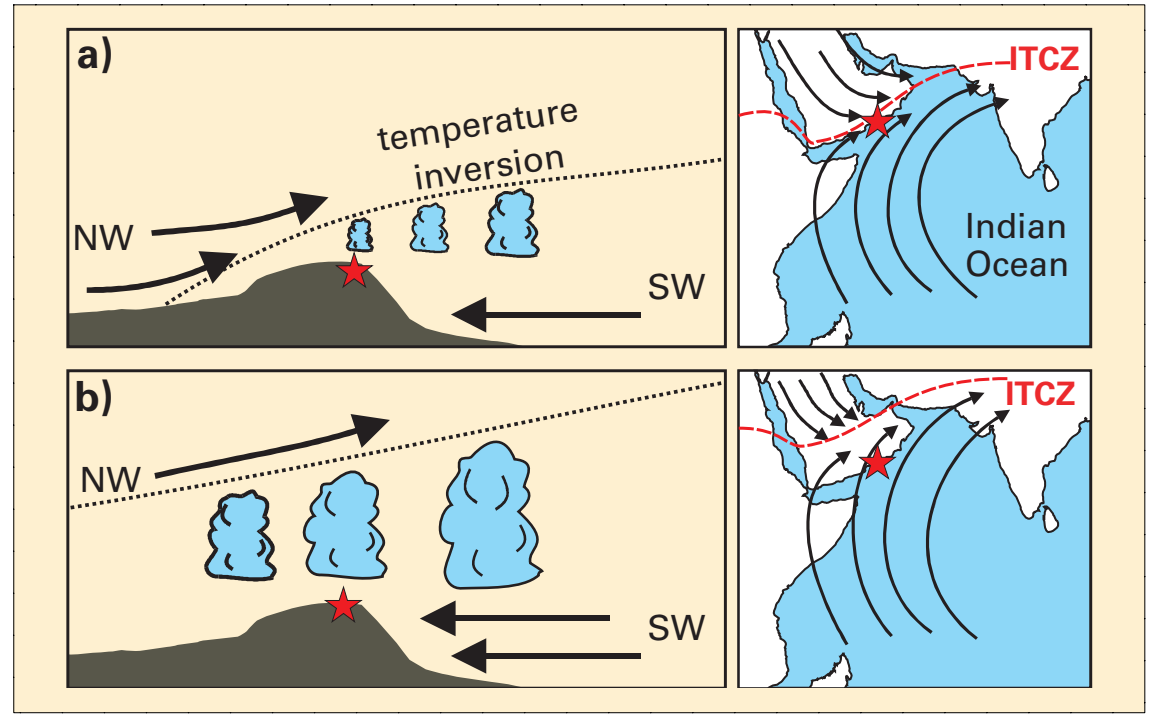

Fig. 1: a Modern summer circulation pattern over Southern Oman. The red star shows the location of Qunf Cave. The black dashed line shows the position of the temperature inversion and the red dashed line the location of the ITCZ. $\boldsymbol{b}$ Schematic figure of summer circulation pattern at around $7 \mathrm{kyr} B P$. 